IS SUPERPLASTICITY IN THE FUTURE OF NANOPHASE MATERIALS?

\author{
R. W. Siegel \\ Materials Science Division \\ Argonne National Laboratory \\ Argonne, IL 60439
}

CONF-900466--96

DE9 1006079

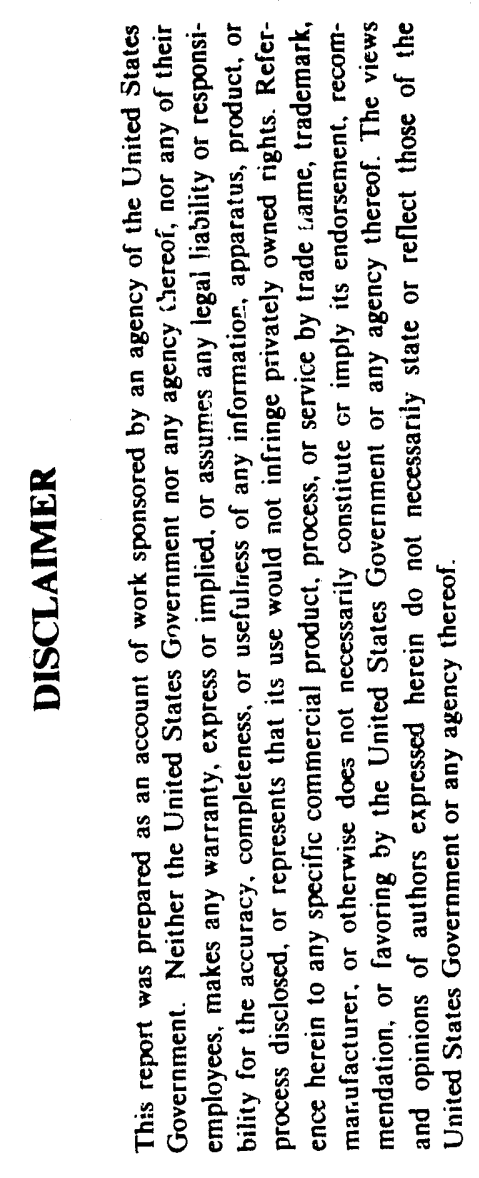

July 1990

INVITED paper to be published in Superplasticity in Metals. Ceramics, and Intermetallics, Materials Research Society Symposium Proceedings, Vol. 196, in press (1990); Editors: M. J. Mayo, J. Wadsworth, et al.

*Work supported by the U. S. Department of Energy, BES-Materials Sciences, under Contract W-31-109-Eng-38.

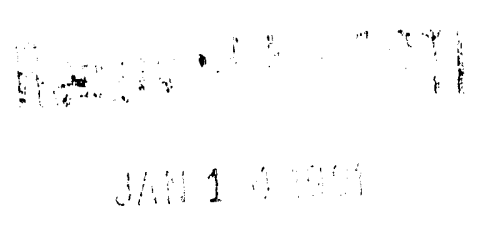

Tho eubritied manuecript hes been authored by a contractor of the U.S. Covernment under the W-31-100-ENG-3a. Accondingly, royally-fres ticenes to publiah or mproduce the published form of this contribution, of allow others to do so, for U.S. Covernment purposes. 


\title{
IS SUPERPLASTICITY IN THE FUTURE OF NANOPHASE MATERIALS?
}

\author{
R. W. SIEGEL
}

Materials Science Division, Argonne National Laboratory, Argonne, Illinois 60439

\begin{abstract}
The ultrafine grain sizes and high diffusivities in nanophase materials assembled from atomic clusters suggest that these materials may have a strong tendency toward superplastic mechanical behavior. Both small grain size and enhanced diffusivity can be expected to lead to increased diffusional creep rates as well as to a significantly greater propensity for grain boundary sliding. Recent mechanical properties measurements at room temperature on nanophase $\mathrm{Cu}, \mathrm{Pd}$, and $\mathrm{TiO}_{2}$, however, give no indications of superplasticity. Nonetheless, significant ductility has been clearly demonstrated in these studies of both nanophase ceramics and metals. The synthesis of cluster-assembled nanophase materials is described and the salient features of what is known of their structure and mechanical properties is reviewed. Finally, the answer to the question posed in the title is addressed.
\end{abstract}

\section{INTRODUCTION}

Over the past few decades $[1,2]$, there has been increasing interest in the possibilities for creating or enhancing superplasticity in a variety of materials, including alloys, intermetallic compounds, and ceramics. Whether the mechanisms that allow for superplastic behavior are dominated by grain boundary sliding, diffusion assisted or not, or diffusional creep, it is apparent that all such mechanisms are expected to be enhanced by small grain sizes, the presence of many high-angle grain boundaries, high atomic mobilities in grain boundaries and/or grains, and grain size stability. It is particularly these features of nanophase materials assembled from atomic clusters that make them so interesting in terms of their potential for superplastic mechanical behavior.

For example, if superplasticity was indeed dominated by diffusional creep, then the strain rate $\mathrm{d} \varepsilon / \mathrm{dt}$ would depend upon the applied stress $\sigma$ as

$$
d \varepsilon / d t=\sigma \Omega / d^{2} k T\left(B_{1} D_{v}+B_{2} \delta D_{b} / d\right)
$$

where $\Omega$ is the atomic volume, $d$ is the mean grain diameter, $B_{1}$ and $B_{2}$ are constants, $D_{v}$ and $D_{b}$ are the bulk (volume) and grain boundary atomic diffusivities, respectively, $\delta$ is the mean effective thickness of the grain boundaries, and kT has its usual meaning. For lower temperatures $\mathrm{T}$ and 
smaller grain sizes $d$, the second term dominates and it is easily seen that the strain rate under these conditions will vary as $D_{b} d^{-3}$. Thus, reducing the average grain size from a conventional value of about $10 \mu \mathrm{m}$ into the nanophase regime of $10 \mathrm{~nm}$, for example, would yield an expected increase in the strain rate $\mathrm{d} \varepsilon / \mathrm{dt}$ by a factor of $10^{9}$. If one furthermore takes into account that the effective grain boundary diffusivity in nanophase materials may be enhanced by as much as a factor of $10^{4}$ at room temperature, a total strain rate enhancement of a factor of $10^{13}$ might be expected [3]. Unfortunately, as has recently been demonstrated $[4,5]$, this appears now to be a significant overestimate of these combined effects on the strain rate behavior of nanophase materials at room temperature. However, this example at least serves to give a feeling for the types of enhancements that might ensue in these interesting new materials.

In the present paper, those aspects of nanophase materials assembled from gas-condensed atomic clusters that are expected to impact on the question of superplasticity are considered. These aspects include the methods of material synthesis and processing that lead to polycrystalline metals and ceramics with mean grain sizes in the range of 5 to $25 \mathrm{~nm}$ and numerous clean high-angle grain boundaries, grain boundary structures and morphologies that result in materials deeply metastable against grain growth, and properties that indicate both a strong propensity for grain boundary sliding and an ability to accommodate such sliding by means of rapid atomc diffusion in their grain boundary regions. A major advantage of cluster-assembled nanophase materials, beyond these structural aspects important for superplasticity, is that a wide range of materials can be produced in this manner. They include metals and alloys, intermetallic compounds, ceramics, and semiconductors. Composites of these materials can also be synthesized by means of the gas-condensation method. However, most of the research carried out to date has concentrated on single-phase metals and ceramics.

\section{SYNTHESIS OF NANOPHASE MATERIALS}

The synthesis of ultrafine-grained materials by the in situ consolidation of nanometer size gas-condensed ultrafine particles or atomic clusters was first suggested by Gleiter [6]. The subsequent application of this idea to the synthesis of a variety of nanophase metals and ceramics over the past several years [3, 7-10] has built upon a considerable body of earlier research into the production of ultrafine particles by means of the gas-condensation method as well as much assembled knowledge on powder metallurgy and ceramics. Earlier research on the gascondensation method and on the resulting atomic clusters [11-13] defined the various parameters that control the sizes of the clusters formed in the conventional gas-condensation method (primarily type of gas, gas pressure, and evaporation rate) that are used to synthesize nanophase materials.

A typical apparatus for the synthesis of nanophase materials via gas-condensation is shown

schematically in Figure 1. It is comprised of an ultrahigh-vacuum (UHV) system fitted with two resistively-heated evaporation sources, a cluster collection device (liquid-nitrogen filled cold finger) 


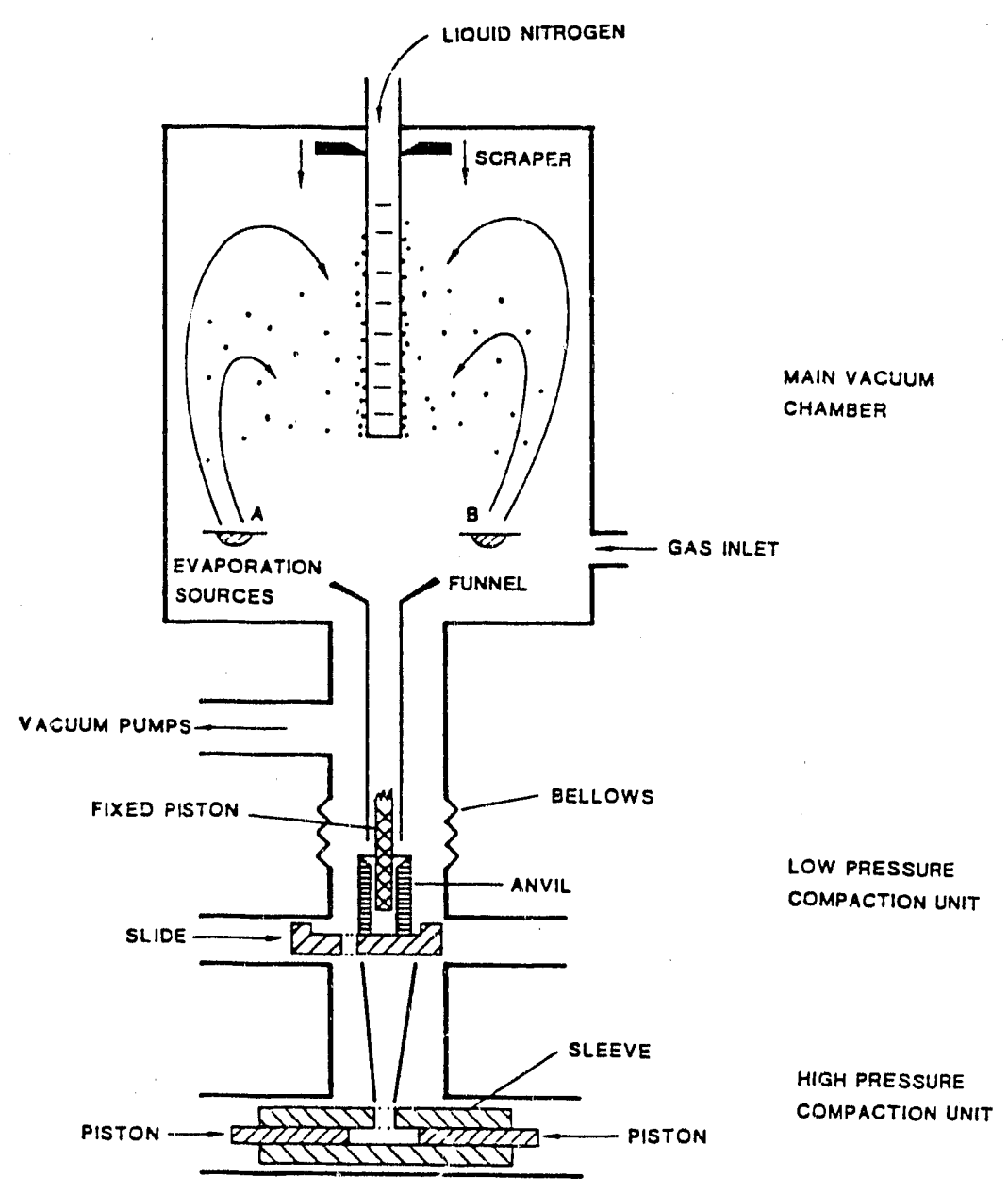

Figure 1. Schernatic drawing of a gas-condensation chamber for the synthesis of nanophase materials. The precursor material evaporated from sources A and/or B condenses in the gas and is transported via convection to the liquid-nitrogen filled cold finger. The powders are subsequently scraped from the cold finger, collected via the funnel, and consolidated first in the low-pressure compaction device and then in the high-pressure compaction device, all in vacuum. From [14].

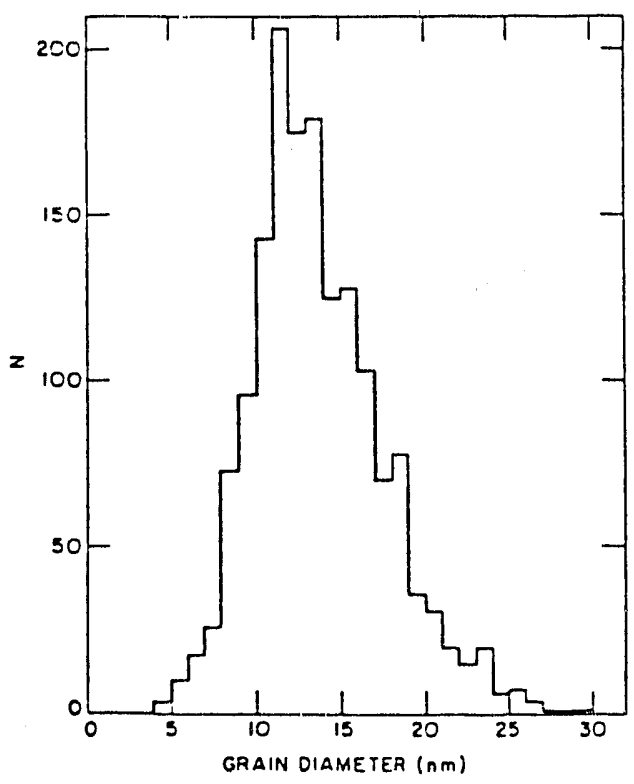

Figure 2. Grain size distribution for a nanophase $\mathrm{TiO}_{2}$ (rutile) sample compacted to $1.4 \mathrm{GPa}$ at room temperature, as determined by transmission electron microscopy. From [20]. 
and scraper assembly, and in situ compaction devices for consolidating the powders produced and collected in the chamber. Before making the powders, the UHV system is first evacuated by means of a turbomolecular pump to below $10^{-5} \mathrm{~Pa}$ and then back-filled with a controlled high-purity gas atmosphere at pressures of about a few hundred $\mathrm{Pa}$. For producing metal powders this is usually an inert gas, such as $\mathrm{He}$, but it can alternatively be a reactive gas or gas mixture if, for example, clusters of a ceramic compound are desired.

During evaporation of the starting precursor material (or materials) from which the nanophase material will be synthesized, atoms conclense in the supersaturated region close to the source and are transported via convection in the gas to the liquid-nitrogen filled cold finger, where they are collected. The gas type and pressure and the precursor evaporation rate, which are easily controlled, determine the resulting particle-size distributions [12] in such an apparatus. The smallest cluster sizes for a given material are obtained for a low precursor evaporation rate and condensation in a low pressure of a light inert gas, such as helium. These conditions lead to a lower supcisaturation of precursor atoms in the gas, slower removal of energy from the evaporated atoms, and more rapid convective gas flow. The latter is important, since it guarantees more rapid removal of the condensed clusters from the supersaturated region in which they grow.

The clusters that are collected on the surface of the cold finger form very open, fractal structures as seen by transmission electron microscopy. They can be easily removed from this collection surface by means of a Teflon scraper and funneled into piston-and-anvil devices (Figure 1) capable of compaction pressures up to about 1-2 GPa, in which the nanophase compacts are formed at room temperature. These pellets are typically about $9 \mathrm{~mm}$ in diameter and 0.2 to $0.5 \mathrm{~mm}$ tilick. The scraping and consolidation is performed under UHV conditions after removal of the inert or reactive gases from the chamber, in order to maximize the cleanliness of the particle surfaces and the interfaces that are subsequently formed, while reducing the possibility of trapping remnants of these gases in the nanophase compact.

Using the conventional gas-condensation method described here, which utilizes convective gas flow, the average cluster diameters produced presently range between about 5 and $25 \mathrm{~nm}$, yielding nanophase materials with such grain sizes. However, more sophisticated applications of the gas-condensation method that utilize forced gas flow have been used by cluster chemists and physicists to produce low yields of even smaller atomic clusters with very narrow, and even monosized, size distributions [15]. Cluster sources based on similar principles can be expected to be available in the future for the generation of larger yields of clusters that will be useful for assembly into nanophase materials.

In addition to the Joule-heated evaporation sources that have normally been used in producing clusters for nanophase materials synthesis, it can be expected that sputtering [16], electron beam [17], plasma [18], or laser ablation [19] methods will provide better control of the evaporation 
parameters. Also, this variety of evaporation methods will allow for the use of refractory or reactive precursors for clusters and will be especially useful as one moves toward synthesizing more complex multicomponent or composite nanophase materials in the future.

\section{STRUCTURE AND STABILITY}

The predominant feature of nanophase materials is their ultrafine grain size and, hence, the large fraction of their atoms that reside in grain boundaries. For example, a nanophase material with a 5 $\mathrm{nm}$ average grain size will have from about 30 to $60 \%$ of its atoms associated with grain boundaries, taking a grain boundary thickness of about 0.5 to $1.0 \mathrm{~nm}$ (ca. 2.4 nearest-neighbor distances). This percentage falls only to about $15-30 \%$ for a $10 \mathrm{~nm}$ grain size, but is as low as $1-3 \%$ for a $100 \mathrm{~nm}$ grain size. The properties of these new materials can therefore be expected to be strongly influenced by the defect nature of their internal boundaries and the electronic-structure changes resulting therefrom, simply because of the very large number density of these boundaries.

The structures of nanophase materials, both metals and oxides, have been investigated by a number of direct and indirect methods including transmission electron microscopy, $x$-ray and neutron scattering, and Mössbauer, Rarnan, and positron annihilation spectroscopy. It has been found that the grains in nanophase compacts are typically rather equiaxed, as are the clusters from which they were assembled, and retain the narrow log-normal size distributions representative of the clusters formed in the gas-condensation method. A typical grain size distribution in a nanophase material, in this case $\mathrm{TiO}_{2}$ with the rutile structure [20], is shown in Figure 2.

In addition to their ultrafine grain sizes, all of the nanophase materials consolidated at room temperature to date have invariably posessed a degree of porosity ranging from about $25 \%$ to less than 5\%, with the larger values for ceramics and the smaller ones for metals. Clear evidence of this porosity has been obtained by positron annihilation spectroscopy $[20,21]$ and precise densitometry and porosimetry $[4,22]$ measurements. Consolidation at elevated temperatures, however, can remove this porosity without sacrificing the ultrafine grain sizes in these materials.

An interesting and technologically important aspect of nanophase materials assembled from atomic clusters is what appears to be an inherent stability against grain growth. Their grain sizes, as measured by transmission electron micros sopy, remain rather deeply metastable to elevated temperatures, and their grain size distributions appear to scale with their growth, when it occurs. For example, the $12 \mathrm{~nm}$ initial average grain diameter for the distribution shown in Figure 2 changes little with annealing to elevated temperatures until about $40-50 \%$ of the absolute melting temperature $\left(\mathrm{T}_{\mathrm{m}}\right)$ of $\mathrm{TiO}_{2}$ is reached. This behavior appears to be rather typical for the nanophase oxides already investigated [10] and for nanophase metals as well [23], as shown in Figure 3. In the case of the $\mathrm{TiO}_{2}$, rapid grain growth only develops above the temperature at which the mean bulk diffusion distance $\left(\mathrm{D}_{\mathrm{Ti}} \mathrm{t}\right)^{1 / 2}$ of its slower diffusing constituent Ti becomes comparable to the 


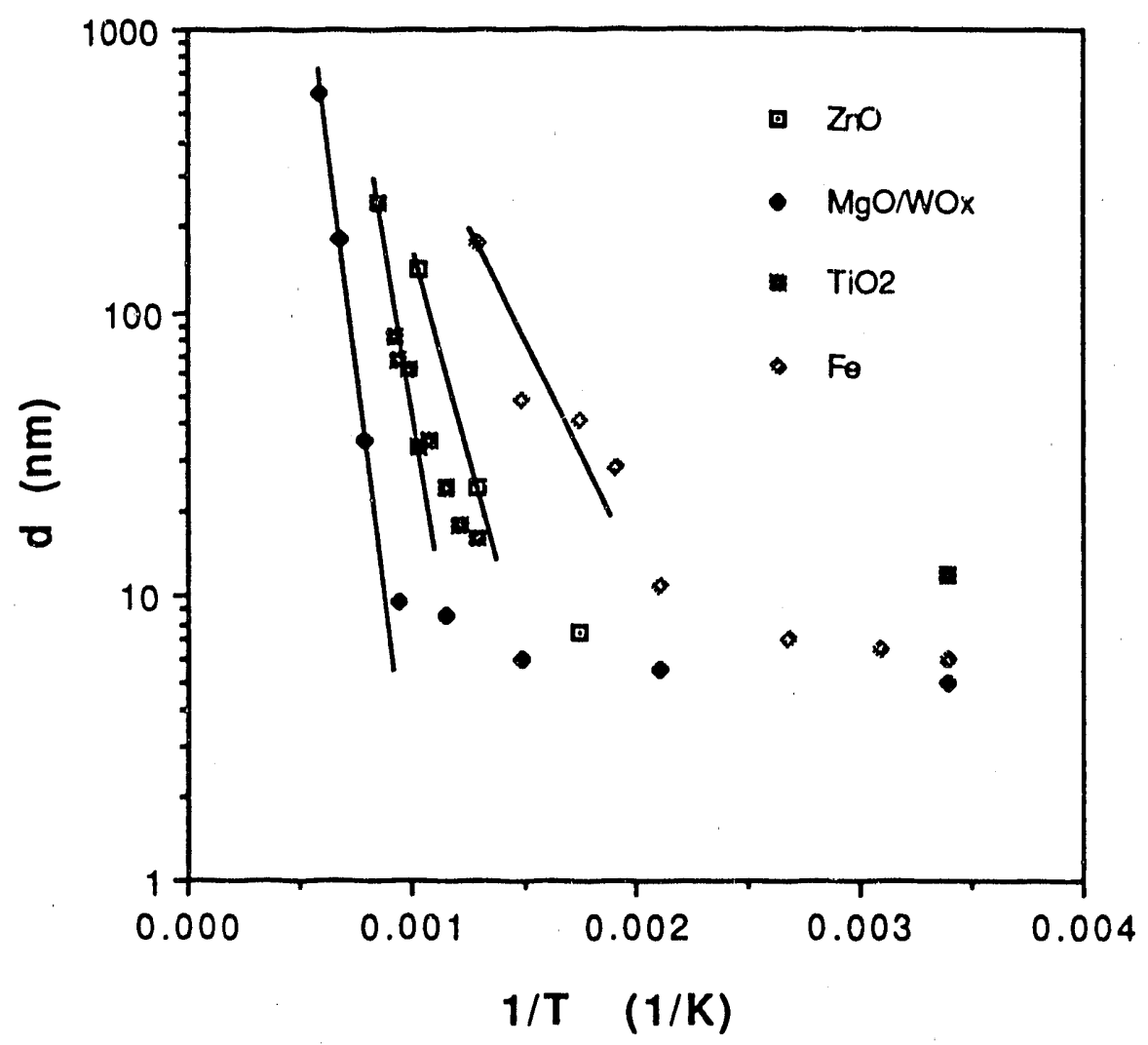

Figure 3. Arrhenius plot of the variation of average grain size, measured by dark-field transmission electron microscopy, with sintering temperature for nanophase $\mathrm{Fe}$ [23], $\mathrm{TiO}_{2}$ [20], $\mathrm{MgO} / \mathrm{WO}_{\mathrm{x}}[10]$, and $\mathrm{ZnO}$ [10]. The oxide samples were annealed for one-half hour in air at each temperature; the iron for 10 hours in vacuum.

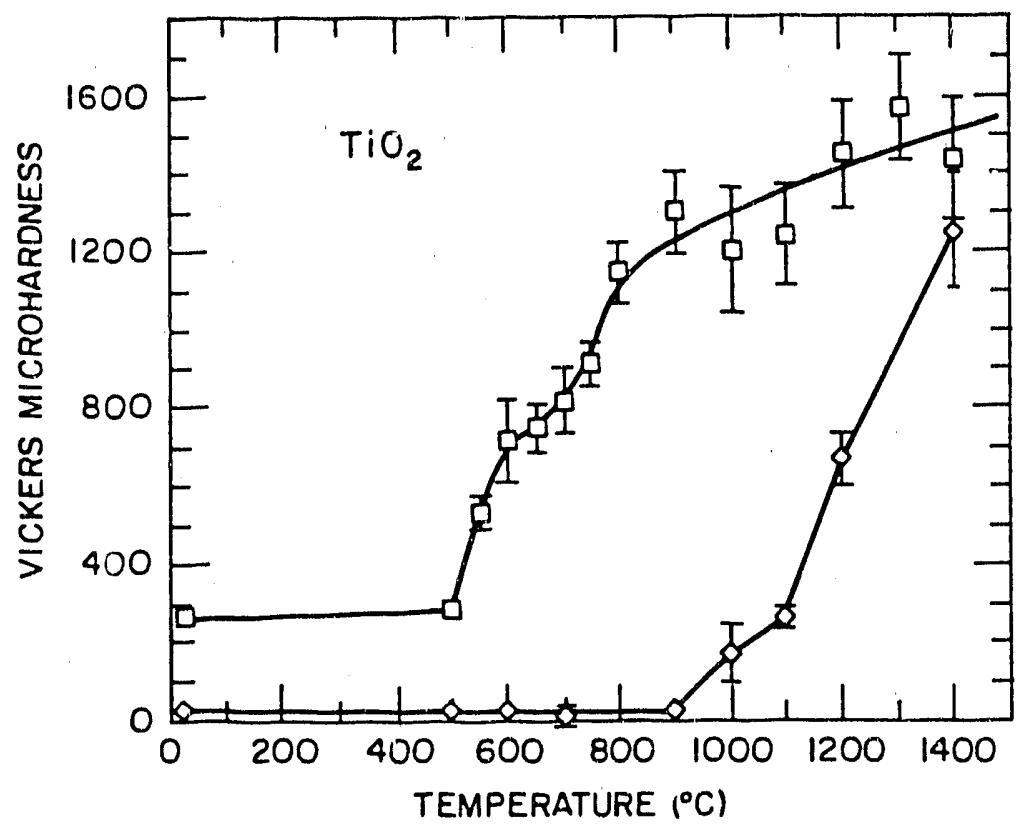

Figure 4. Vickers microhardness in $\mathrm{kgf} / \mathrm{mm}^{2}$ of $\mathrm{TiO}_{2}$ (rutile) measured at room temperature as a function of one-half hour sintering at successively increased temperatures. Results for a nanophase sample (squares) with an initial average grain size of $12 \mathrm{~nm}$ consolidated at $1.4 \mathrm{GPa}$ are compared with those for a coarser-grained sample with $1.3 \mu \mathrm{m}$ initial average grain size sintered with the aid of polyvinyl alcohol from commercial powder consolidated at $0.1 \mathrm{GPa}$. After $[8,20]$. 
mean grain size, at which temperature any losal barriers to grain growth would cease to be significant. Before discussing this grain size rnetastability further, it is useful to consider the nature of the grain boundaries in nanophase materials.

Since such a large fraction of their atoms reside in their grain boundaries, the interface structures can play a significant rôle in determining the properties of nanophase materials. A number of investigations on nanocrystalline metals by Gleiter and coworkers [3], including $\mathrm{x}$-ray diffraction, Mössbauer spectroscopy, positron lifetime studies, and most recently EXAFS, have been interpreted in terms of grain boundary atomic structures that may be random, rather than possessing either the short-range or long-range order normally found in the grain boundaries of coarser-grained polycrystalline materials. However, recent investigations of nanophase Pd by atomic resolution transmission electron microscopy [24] and of nanophase $\mathrm{TiO}_{2}$ by Raman spectroscopy [25] indicate that the grain boundary structures in these materials are quite normal. The boundaries appear to contain short-range ordered structural units representative of the bulk material and distortions that are localized to about $\pm 0.2 \mathrm{~nm}$ on either side of the grain boundary plane. The electron microscopy has also shown that the grain boundary planes are basically flat, but exhibit some local faceting. Such observations suggest at least two conclusions: first, that the atoms that constitute the grain boundary volume in nanophase materials have sufficient mobility during cluster consolidation to accommodate themselves into relatively low energy grain boundary configurations; and second, that the local driving forces for grain growth are relatively small, despite the large amount of energy stored in the many grain boundaries in these materials.

Given these various observations and conclusions regarding the grain size distributions and grain boundaries in nanophase materials, it seems likely that the resistance to grain growth observed for nanophase materials results from frustration [27]. It is postulated that the narrow grain size distributions normally observed in these cluster-assembled materials coupled with their relatively flat grain boundary configurations (and also enhanced by their multiplicity of grain boundary junctions) place these nanophase structures in a local minimum in energy from which they are not easily extricated. They are thus analogous to a variety of closed-cell foam structures, which are stable (really deeply metastable) despite their large stored surface energy. Under such conditions, only at temperatures above which bulk diffusion distances are comparable to or greater than the grain size, as in the case of nanophase $\mathrm{TiO}_{2}$ cited above, will this metastability give way to global energy minimization via rapid grain growth. Such diffusion controlled behavior is apparent when one observes the high-temperature data shown in Figure 3. However, the effective activation energy of this high temperature limiting behavior is only about $9 \mathrm{kT}_{\mathrm{m}}$, or approximately one half that for self-diffusion. Exceptions to this frustrated grain growth behavior could be expected if considerably broader grain size distributions were present in a sample, which would allow a few larger grains to grow at the expense of smaller ones, or if significant grain boundary contamination were present, allowing enhanced stabilization of the small grain sizes to further elevated temperatures. 


\section{MECHANICAL PROPERTIES}

Nanophase materials have a variety of properties that are different and often considerably improved in comparison with those of conventional coarse-grained structures. For example, nanophase $\mathrm{TiO}_{2}$ (rutile) exhibits significant improvements in both sinterability and resulting mechanical properties relative to conventionally synthesized coarser-grained rutile $[5,20,22,28]$. Nanophase $\mathrm{TiO}_{2}$ with a $12 \mathrm{~nm}$ initial mean grain diameter has been shown [20] to sinter under ambient pressures at 400 to $600^{\circ} \mathrm{C}$ lower temperatures than conventional coarse-grained rutile, and without the need for any compacting or sintering aid, which is usually required. This behavior is shown in Figure 4. More recently, it has been demonstrated [22] that sintering the same nanophase material under pressure $(1 \mathrm{GPa})$ can reduce the sintering temperatures even further. In addition, such processing appears to suppress grain growth during sintering as well, showing clearly that the grain size stability in this material is not associated with void (pore) pinning of the grain boundaries. The resulting fracture characteristics $[22,28]$ developed for nanophase $\mathrm{TiO}_{2}$ are also improved relative to those for conventional rutile. It may not be terribly surprising that nanophase ceramics, with their ultrafine grain sizes, clean cluster surfaces, and high grain boundary purity, will sinter at much lower temperatures than conventional coarser-grained ceramics. However, it is unique that they can also retain their fine grain sizes after sintering to full density and exhibit superior mechanical properties as well.

Beyond their enhanced sinterability and fracture characteristics, nanophase ceramics are easily formed, as is clearly evident in the sample compaction process [20] and from demonstrations via deformation [29] as well. However, the degree to which nanophase ceramics are truly ductile is only beginning to be understood. Nanoindenter measurements [5] on nanophase $\mathrm{TiO}_{2}$ have recently demonstrated that a dramatic increase of strain rate sensitivity occurs with decreasing grain size, as shown in Figure 5. Since this strong grain-size dependence is found for a set of samples in which the porosity is changing very little, it appears to be an intrinsic property of the ultrafine grained material. The strain rate sensitivity $(\mathrm{m})$ values at the smallest grain size yet investigated (12 $\mathrm{nm}$ ) thus indicate ductile behavior of this nanophase ceramic, as well as a significant potential for increased ductility at even smaller grain sizes. The maximum strain rate sensitivity measured for the nanophase $\mathrm{TiO}_{2}$, nearly 0.04 , is already approximately one-quarter that for lead at room temperature, for example. However, no superplasticity has yet been observed in nanophis. materials at room temperature, which would yield $\mathrm{m}$ values about an order of magnitude higher than the maximum observed.

The dominant mechanical property change resulting from reduring the grain sizes of nanophase metals is the significant increase in their strength. While the microhardness of as-consolidated nanophase oxides is reduced relative to their fully dense counterparts, owing to significant porosity in addition to their ultrafine grain sizes, the case for nanophase metals is quite different. Figure 6 shows recent microhardness results for nanophase palladium and coarser-grained samples as a 


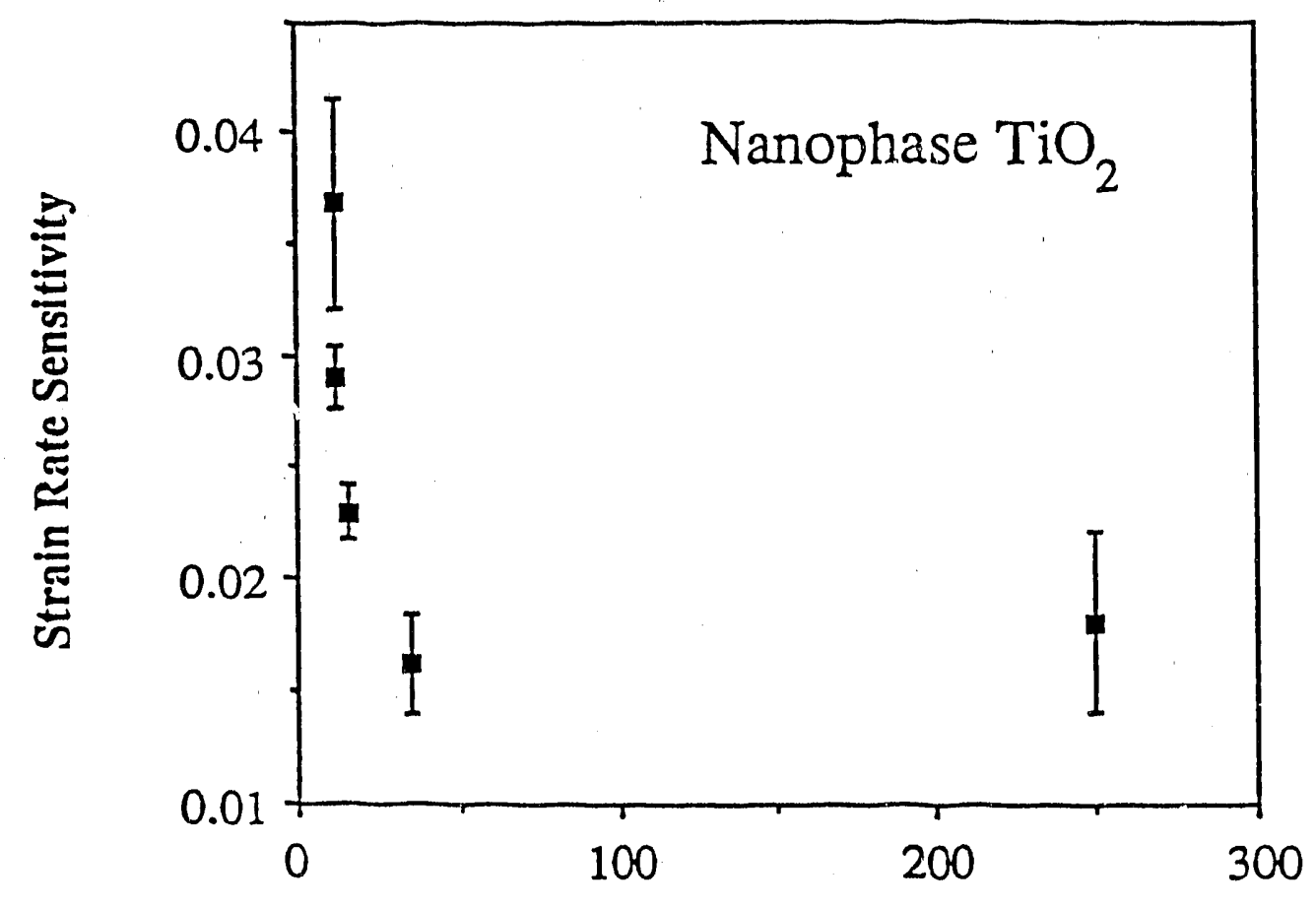

Grain Size (nm)

Figure 5. Strain rate sensitivity of nanophase $\mathrm{TiO}_{2}$ as a function of its grain size. The strain rate sensitivity was measured by a nanoindentation method and the grain size was determined by dark-field transmission electron microscopy. From [5].

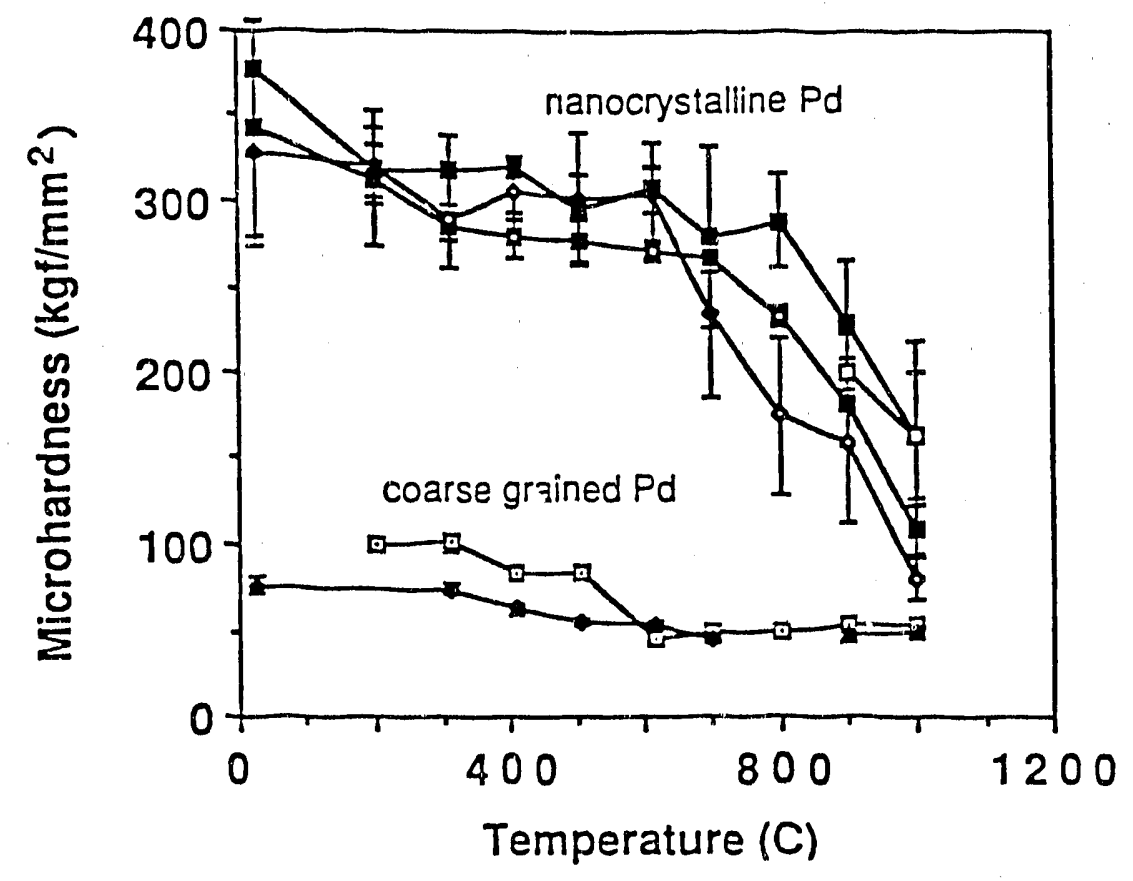

Figure 6. Microhardness of three nanocrystalline $(5-10 \mathrm{~nm})$ palladium samples and two coarse-grained $(100 \mu \mathrm{m})$ palladium samples as a function of annealing temperature. All samples were annealed for 100 minutes in $0.16 \mathrm{~Pa}$ vacuum and measured subsequently at room temperature. From [4]. 
function of annealing [4]. In the as-consolidated state, the nanophase palladium samples with 5-10 $\mathrm{nm}$ grain sizes exhibit a four-fold increase in hardness over the coarser-grained (ca. $100 \mu \mathrm{m}$ ) samples. Similar results have been observed in nanophase copper as well [4]. As shown in Figure 6, up to about $50 \%$ of its absolute melting temperature, the hardness of nanophase Pd falls only slowly with annealing, commensurate with the rather deep observed grain size metastability in these materials cited above. The increased strength in these ultrafine grain size metals, which is supported by yield stress measurements [4], although analogous to conventional Hall-Petch strengthening observed with decreasing grain size in coarser-grained metals, must result from fundamentally different mechanisms. The description of the mechanisms responsible for the increased strength observed in nanophase metals will need to be accommodated to the grain-size scale in these materials. After all, the grain sizes here are smaller than the necessary critical bowing lengths for Frank-Read dislocation sources to operate and smalier than the normal spacings between dislocations in a pile-up, as well.

Atomic diffusion in nanophase materials, which has a significant bearing on mechanical properties such as creep and superplasticity, has been found to be very rapid. Measurements of self-diffusion and impurity-diffusion $[22,30,31]$ in as-consolidated nanophase metals and ceramics indicate that atomic transport is orders of magnitude faster in these materials than in coarser-grained polycrystalline samples. However, the predicted [32] magnitude of the creep enhancement associated with this fast diffusion appears to be too large. Recent constant-stress creep measurements on nanophase $\mathrm{Pd}$ and $\mathrm{Cu}$ [4] show that the observed creep rates at room temperature are at least three orders of magnitude smaller than predicted on the basis of the overly simple Coble creep model outlined in the Introduction. The very rapid diffusion in as-consolidated nanophase materials appears to be intrinsically coupled with the porous nature of the interfaces in these materials, and can be suppressed back to conventional values by sintering samples to full density [22]. Nonetheless, there exist considerable possibilities for efficiently doping nanophase materials via the rapid diffusion available along their ubiquitous grain-boundary networks to synthesize materials with tailored optical, electrical, or mechanical properties.

\section{PROGNOSIS FOR SUPERPLASTICITY}

It should already be clear from the foregoing that the unique structure and properties of nanophase materials indicate that they should indeed be fertile ground for superplastic mechanical behavior. However, as of this writing, no such superplasticity has been demonstrated. Nevertheless, it already seems clear that in the future, at smaller grain sizes and/or at elevated temperatures, superplasticity of these materials will be observed. Indeed, very recent experiments $[33,34]$ on nanophase $\mathrm{TiO}_{2}$ at temperatures around $800^{\circ} \mathrm{C}$, which indicate this material's capacity for large-scale deformation, are already encouraging in this regard.

The enhanced strain rate sensitivity at room temperature found in nanophase $\mathrm{TiO}_{2}[5]$ appears to 
result from increased grain boundary sliding in this material, aided by the presence of porosity, ultrafine grain size, and probably rapid diffusion as well. The increased strength of nanophase metals [4], on the other hand, indicates that dislocation generation, as well as dislocation mobility, may become significantly difficult in ultrafine-grained metals. It may thus be that the increased strength of nanophase metals and the increased ductility of nanophase ceramics indicate a convergence of the mechanical response of these two classes of materials as grain sizes enter the nanometer size range. In such a case, grain boundary sliding mechanisms, accompanied by short-range diffusion assisted healing events, would be expected to increasingly dominate the deformation of nanophase materials, and superplasticity in a wide range of materials including metals and alloys, intermetallic compounds, ceramics, and even semiconductors could result.

Clearly, much work remains to be done in this area in order to fully elucidate the deformation behavior and mechanisms in nanophase metals and oxides, and to extend these studies to other classes of ultrafine-grained materials. The ability to now synthesize under controlled conditions a broad spectrum of materials via the assembly of gas-condensed atomic clusters, producing stable ultrafine-grained polycrystals with clean grain boundaries, should provide many new opportunities for the study and engineering of new superplastic materials in the future.

This work was suppor ted by the U.S. Department of Energy, BES-Materials Sciences, under Contract W-31-109-Eng-38.

\section{REFERENCES}

1. O. D. Sherby, these Proceedings.

2. T. G. Nieh, C. M. McNally, and J. Wadsworth, J. Metals 41(9), 31 (1989).

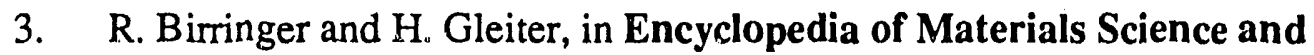
Engineering, Suppl. Vol. 1, R. W. Cahn, ed. (Pergamon Press, Oxford, 1988) p. 339.

4. G. W. Nieman, J. R. Weertman, and R. W. Siegel, Scripta Metall. 23, 2013 (1989); Ibid. 24, 145 (1990).

5. M. J. Mayo, R. W. Siegel, A. Narayanasamy, and W. D. Nix, J. Mater. Res. 5, 1073 (1990).

6. H. Gleiter, in Deformation of Polycrystals: Mechanisms and Microstructures,

N. Hansen et al., eds. (Risø National Laboratory, Roskilde, 1981) p. 15.

7. R. Birringer, U. Herr, and H. Gleiter, Suppl. Trans. Jpn. Inst. Met. 27, 43 (1986).

8. R. W. Siegel and H. Hahn, in Current Trends in the Physics of Materials, M. Yussouff, ed. (World Scientific Publ. Co., Singapore, 1987) p. 403.

9. H. Hahn, J. A. Eastman, and R. W. Siegel, in Ceramic Transactions, Ceramic Powder Science, Vol. 1, Part B, G. L. Messing et al., eds. (American Ceramic Society, Westerville, 1988) p. 1115. 
10. J. A. Eastman, Y. X. Liao, A. Narayanasamy, and R. W. Siegel, Mater. Res. Soc. Symp. Proc. 155, 255 (1989).

11. K. Kimnto, Y. Kamiya, M. Nonoyama, and R. Uyeda, Jpn. J. Appl. Phys. 2, 702 (1963).

12. C. G. Granquist and R. A. Buhrman, J. Appl. Phys. 47, 2200 (1976).

13. A. R. Thölén, Acta Metall. 27, 1765 (1979).

14. R. W. Siegel and J. A. Eastman, Mater. Res. Soc. Symp. Proc. 132, 3 (1989).

15. R. P. Andres, R. S. Averback, W. L. Brown, L. E. Brus, W. A. Goddard, III, A. Kaldor, S. G. Louie, M. Moskovits, P. S. Peercy, S. J. Riley, R. W. Siegel, F. Spaepen, and Y. Wang, J. Mater. Res. 4, 704 (1989).

16. H. Hahn and R. S. Averback, J. Appl. Phys. 67, 1113 (1990).

17. S. Iwama, K. Havakawa, and T. Arizumi, J. Cryst. Growth 56, 265 (1982).

18. A. Matsunawa and S. Katayama, in Laser Welding, Machining and Materials Procescing, Proc. ICAlEO '85, C. Albright, ed. (IFS Publ. Ltd.,1985).

19. K. Baba, N. Shohata, and M. Yonezawa, Appl. Phys. Lett. 54, 2309 (1989).

20. R. W. Siegel, S. Ramasamy, H. Hahn, Z. Li, T. Lu, and R. Gronsky, J. Mater. Res. 3, 1367 (1988).

21. H.-E. Schaefer, R. Würschum, R. Birringır, and H. Gleiter, Phys. Rev. B 38, 9545 (1988).

22. R. S. Averback, H. Hahn, H. J. Hötler, J. L. Logas, and T. C. Chen, Mater. Res. Soc. Symp. Proi. 153, 3 (1989).

23. E. Hort, Diploma Thesis, Universität des Saarlandes, Saarbrücken (1986).

24. G. J. Thomas, R. W. Siegel, and I. A. Eastmi n, Mater. Res. Soc. Symp. Proc. 153, 13 (1989); Scripta Metall. 24, 201 (1990).

25. C. A. Melendres, A. Narayanasamy, V. A. Maroni, and R. W. Siegel, J. Mater. Res. 4, 1246 (1989).

26. J. E. Epperson, R. W. Siegel, J. W. White, T. E. Klippert, A. Narayanasamy, J. A. Eastman, and F. Trou', Mater. Res. Soc. Symp. Proc. 132, 15 (1989).

27. R. W. Siegel, Brill. Amer. Phys. Soc. 35, 411 (1990)

28. Z. Li, S. Ramasamy, H. Hahn, and R. W. Siegel, Mater. Lett. 6, 195 (1988).

29. J. Karch, R. Birringer, and H. Gleiter, Nature 330, 556 (1987).

30. J. Horvåth, R. Birrirger, and H. Gleiter, Solid State Commun. 62, 319 (1987).

31. J. Horváth, Defect and Diffusion Forum 66-69, 207 (1989).

32. R. Birringer, H. Hahn, H. Höfler, J. Karch, and H. Gleiter, Defect and Diffusion Forum 59, 17 (1988).

33. H. Hahn, J. Logas, H. J. Höfler, and R. S. Averback, these Proceedings.

34. J. Karch and R. Birringer, Ceramics International 16, in press (1990). 

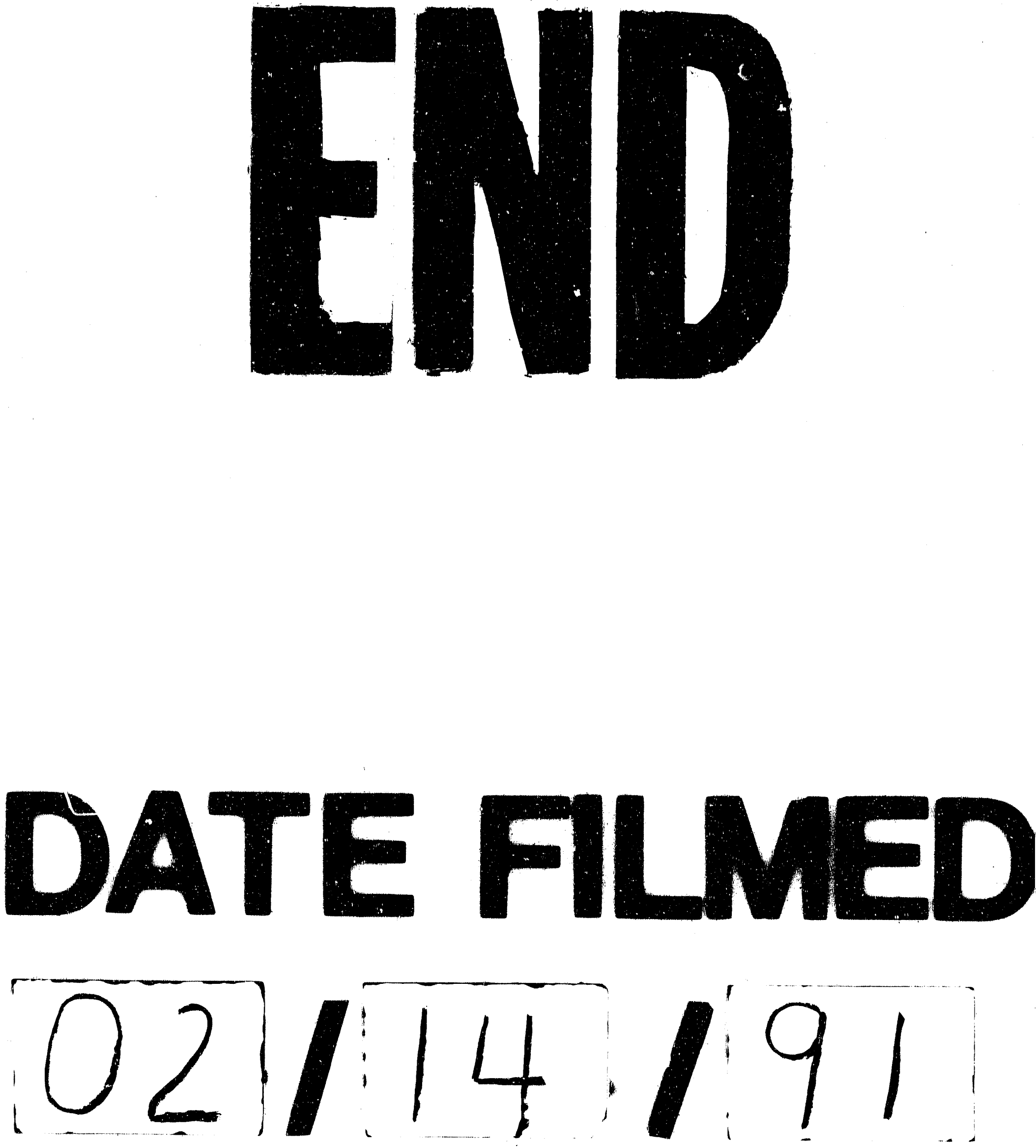


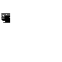

